\title{
Analysis of the most common causes of blood donor deferral in northern Jeddah: a single-center study
}

This article was published in the following Dove Medical Press journal: Journal of Blood Medicine

\author{
Afnan K AINouri' \\ Lamees A Maghrabi' \\ Samah S Hamdi' \\ Shereen M Abd El-Ghany ${ }^{2,3}$ \\ Khalid A AINouri ${ }^{4}$ \\ 'College of Medicine, Ibn Sina \\ National College for Medical Studies, \\ Jeddah, Kingdom of Saudi Arabia; \\ ${ }^{2}$ Department of Pediatrics, Ibn \\ Sina National College for Medical \\ Studies, Jeddah, Kingdom of Saudi \\ Arabia; ${ }^{3}$ Department of Pediatrics, \\ Hematology and Oncology Unit, \\ Ain Shams University, Cairo, Egypt; \\ ${ }^{4}$ Department of Intensive Care, King \\ Abdulaziz University Hospital, Jeddah, \\ Kingdom of Saudi Arabia
}

Purpose: We aimed to conduct a retrospective study in order to statistically analyze the commonest causes for blood donor rejection in northern Jeddah, Kingdom of Saudi Arabia according to the American Association of Blood Banks. This will help in developing better strategies to minimize the loss of treasured blood donors.

Subjects and methods: A sample of 500 rejected donors was randomly selected from a single blood bank between October 2016 to May 2017. The evaluation of blood donors was according to the personal history questionnaire and a medical examination done before the blood donation proceeded.

Results: The causes of deferral were categorized into three main categories: personal factors, medical examination and medical history. The most common personal cause of deferral was lack of sleep (29 [5.80\%]); however, the most common medical examination cause of deferral was low blood pressure (68 [13.60\%]). Concerning the medical history, the commonest cause was cupping (58 [11.6\%]).

Conclusion: Low blood pressure (13.6\%), cupping (11.6\%) and less hours of sleep in the night prior to donation $(5.8 \%)$ were the major causes of rejection in this study. Similarities and variations between the commonest causes of blood donor rejection may be due to the differences and similarities in the geographic area and in the cultural, educational and socioeconomic factors.

Keywords: cupping, donor questionnaire, blood transfusion, safe blood

\section{Introduction}

Blood donation is considered as an important life-saving practice in medicine, especially in cases of medical emergency. ${ }^{1}$

The need for blood is universal; however, millions of patients who may need transfusion do not have timely access to safe blood, and there is a major imbalance between the developing and developed countries in access to safe blood. Safe blood transfusion is a major concern that needs the application of science and technology to blood processing and testing, as well as social efforts to promote blood donation by sufficient numbers of volunteers who are healthy and are at low risk of infections that can be transmitted to the recipients of their blood. ${ }^{2}$

The WHO Global Database indicated that $>92$ million blood donations are collected annually from 164 different countries around the world. Around 1.6 million units were discarded due to the presence of infections such as hepatitis B and C, HIV, herpes and syphilis. In addition, at least 13 million donors were deferred due to having the risk of infection that could be transmitted through blood, a preexisting medical disease or
Correspondence: Afnan K AINouri College of Medicine, Ibn Sina National College for Medical Studies, 2242I, A Mahjar Street, Jeddah, Saudi Arabia Tel +966 I2 6355882

Email afnan.alnouri@gmail.com 
anemia. ${ }^{3}$ Due to this, blood donor selection is a cornerstone for blood transfusion safety, designed to safeguard the health of both donors and recipients. ${ }^{4}$ Blood donor eligibility is determined by medical interview, based on national guidelines for donor selection. ${ }^{5}$

The key tool for blood donor selection would be a "donor questionnaire" that would assess a donor's health and history that would help assess if the donor has any risk for having infection that could be transmitted by blood and furthermore has no suitable screening test. After that, a confidential interview is conducted between the donor and a member staff to ensure that all questions are answered relevantly. ${ }^{3}$

Many studies have been conducted around the world concerning the causes for blood donor deferral, such as in Brazil, Turkey, India, Singapore, Dubai and Dammam, which is in the eastern region of Kingdom of Saudi Arabia. ${ }^{6-11}$ Another study was conducted in the southern region of Jeddah; however, no study was carried out in the northern region of Jeddah, Kingdom of Saudi Arabia. ${ }^{12}$ In this study, we aimed to analyze the commonest causes for blood donor deferral in northern Jeddah, Kingdom of Saudi Arabia.

\section{Subjects and methods}

This cross-sectional study was conducted at King Abdullah Medical Complex, a major hospital in northern Jeddah, Kingdom of Saudi Arabia between October 2016 to May 2017. Ethical approval was obtained from the Directorate of Health Affairs, Department of Medical Research and Study, Jeddah. Data were held confidentially. This study was conducted in accordance with The Code of Ethics of the World Medical Association (Declaration of Helsinki) for experiments in humans. Informed consent was not needed because the study was conducted retrospectively. Data were collected from the records in the blood bank and then analyzed. About 400 donors came to apply for donation per month, including both Saudis and non-Saudis. About 20\% of them underwent rejection. A sample of 500 deferred donors was selected; all were Saudis. Data were entered using Google Forms and then further analyzed by Microsoft Excel. Data were presented as numbers and percentages. The evaluation of all blood donors who came to apply for donation was done according to a questionnaire that included questions of personal history of behaviors, traveling and medical conditions. After that, the intended blood donor underwent a medical examination consisting of weight, height, vital signs and hemoglobin level. The American Association of Blood Bank's guidelines and the blood bank's guidelines were used for either selection or rejection.
All the donors were educated and the process of donation was fully explained to them. The donors were confidentially requestioned orally about certain risk behaviors, history of traveling and many other conditions that would eventually affect the recipient's safety. All this was done to make sure of the donor's eligibility.

\section{Results}

This study was conducted on 500 selected Saudi deferred blood donors. Most of those who were rejected were males (428 [85.6\%]) and the rest were females (72 [14.4\%]), as shown in Table 1. Their ages ranged from 16 to 76 years, with most of them aged between 21 and 25 years (119 [23.8\%]), as shown in Table 2 .

The deferral of blood donors was categorized under three main categories: personal causes, causes due to significant medical examination and other causes due to a donor's history. Table 1 also illustrates that $236(47.20 \%)$ were deferred due to significant medical examination, $213(42.60 \%)$ due to significant history and only 51 (10\%) were rejected due to personal issues.

Concerning the personal causes for deferred blood donors, the commonest was that the intended blood donor was not getting enough sleep in the night prior to donation (29 [5.80\%]), as shown in Table 3.

Regarding the examination causes for rejection, the commonest was that the donor had low blood pressure (68

Table I Gender distribution and categories of causes of deferral

\begin{tabular}{|l|l|}
\hline Gender & No. deferred (\%) \\
\hline Male & $428(85.6)$ \\
\hline Female & $72(14.4)$ \\
\hline Category of causes of deferral & No. deferred (\%) \\
\hline Personal causes & $51(10 \%)$ \\
\hline Examination causes & $236(47.20 \%)$ \\
\hline History causes & $213(42.60 \%)$ \\
\hline
\end{tabular}

Table 2 Age ranges of the deferred donors

\begin{tabular}{|l|l|}
\hline Age ranges in years & No. deferred (\%) \\
\hline $16-20$ & $38(7.6)$ \\
\hline $2 I-25$ & $119(23.8)$ \\
\hline $26-30$ & $99(19.8)$ \\
\hline $3 I-35$ & $87(17.4)$ \\
\hline $36-40$ & $68(13.6)$ \\
\hline $4 I-45$ & $34(6.8)$ \\
\hline $46-50$ & $19(3.8)$ \\
\hline $5 I-55$ & $20(4)$ \\
\hline $56-60$ & $12(2.4)$ \\
\hline $62-76$ & $4(0.8)$ \\
\hline Total & $\mathbf{5 0 0 ( 1 0 0 )}$ \\
\hline
\end{tabular}


Table 3 The personal causes for blood donor deferral

\begin{tabular}{|l|l|}
\hline Personal Causes & No. of deferred (\%) \\
\hline Less sleep hours & $29(5.8)$ \\
\hline Old age & $8(1.6)$ \\
\hline No vein & $6(1.2)$ \\
\hline No ID & $3(0.6)$ \\
\hline Young age & $3(0.6)$ \\
\hline Didn't come back & $2(0.4)$ \\
\hline Total & $\mathbf{5 I ~ ( 1 0 \% ) ~}$ \\
\hline
\end{tabular}

Table 4 The examination causes for blood donor deferral

\begin{tabular}{|l|l|}
\hline Examination causes & No. deferred (\%) \\
\hline Low blood pressure & $68(13.6)$ \\
\hline Low hemoglobin & $54(10.8)$ \\
\hline High hemoglobin & $35(7)$ \\
\hline High blood pressure & $28(5.6)$ \\
\hline High pulse & $22(4.4)$ \\
\hline Low weight & $14(2.8)$ \\
\hline Low pulse & $7(1.4)$ \\
\hline Fever & $3(0.6)$ \\
\hline Increased weight & $3(0.6)$ \\
\hline Palpitations & $\mathrm{I}(0.2)$ \\
\hline Fainted during blood pressure measurement & $\mathrm{I}(0.2)$ \\
\hline Total & $\mathbf{2 3 6}(\mathbf{4 7 . 2 0 \% )}$ \\
\hline
\end{tabular}

[13.60\%]), followed by low hemoglobin (54 [10.80\%]), high hemoglobin (35 [7\%]) and high blood pressure (28 [5.6\%]), as shown in Table 4.

A donor's previous history of some personal behaviors, medical conditions or even traveling was also taken in to consideration as a cause of refusal. The most frequent was that the donor had undergone cupping (58 [11.6\%]), followed by antibiotic ingestion (32 [6.4\%]), dental causes (18 [3.6\%]) and having undergone an operation $(16[3.2 \%])$, as shown in Table 5. Least causes of rejection in this study included infectious disease such as malaria $(2[0.4 \%])$, hepatitis (2 [0.4\%]), sexually transmitted diseases (2 [0.4\%]), hepatitis B virus antibodies (1 $[0.2 \%])$ and HIV $(1[0.2 \%])$. There were other deferral causes such as history of having a nonmarital sexual relation (3 $[0.6 \%])$, tattoo in the past 3 months (1 $[0.2 \%])$, visited Africa $1(0.2 \%)$ and visited Sudan less than a year ago (1 [0.2\%]), all of which increase the risk of exposure to various infectious diseases. Other least common purposes in this category are mentioned in Table 5.

\section{Discussion}

Billions of blood groups and their products are transfused every year all around the world. In the USA, about 13.6 million units of red blood cells and whole blood were transfused in $2013 .{ }^{13}$ Donors who come to the blood bank have
Table 5 A donor's history, which caused deferral

\begin{tabular}{|c|c|}
\hline History & No. of deferred (\%) \\
\hline Cupping & $58(I 1.6)$ \\
\hline On Antibiotic & $32(6.4)$ \\
\hline Dental procedure & $18(3.6)$ \\
\hline Operation & $16(3.2)$ \\
\hline Injection in past 8 weeks & $7(1.4)$ \\
\hline Growth hormone & $6(1.2)$ \\
\hline Donated in past 8 weeks & $6(1.2)$ \\
\hline Asthma & $6(1.2)$ \\
\hline Aspirin & $4(0.8)$ \\
\hline Leukemia & $4(0.8)$ \\
\hline Travelled outside Saudi Arabia recently & $4(0.8)$ \\
\hline Dizziness & $3(0.6)$ \\
\hline Allergy & $3(0.6)$ \\
\hline On insulin & $3(0.6)$ \\
\hline Chest pain & $3(0.6)$ \\
\hline Sexual relations (non-marital) & $3(0.6)$ \\
\hline On medications & $3(0.6)$ \\
\hline Heart/lung disease & $2(0.4)$ \\
\hline Donated one month ago & $2(0.4)$ \\
\hline Eczema & $2(0.4)$ \\
\hline Diabetic & $2(0.4)$ \\
\hline Malaria & $2(0.4)$ \\
\hline Hepatitis & $2(0.4)$ \\
\hline Sexually transmitted disease & $2(0.4)$ \\
\hline Tattoo in the past 3 months & $\mathrm{I}(0.2)$ \\
\hline Visited Africa & $\mathrm{I}(0.2)$ \\
\hline Donated 2 units in past 16 weeks & $\mathrm{I}(0.2)$ \\
\hline Common cold & $\mathrm{I}(0.2)$ \\
\hline Bone/skin grafting & $\mathrm{I}(0.2)$ \\
\hline Post-cesarean section since 10 months & $\mathrm{I}(0.2)$ \\
\hline Psychiatric pills & $\mathrm{I}(0.2)$ \\
\hline Used needles & $\mathrm{I}(0.2)$ \\
\hline Drugs & $\mathrm{I}(0.2)$ \\
\hline Plasma injection & $\mathrm{I}(0.2)$ \\
\hline Transplantation & $\mathrm{I}(0.2)$ \\
\hline Hepatitis B Virus (HBV) antibodies & $\mathrm{I}(0.2)$ \\
\hline On hormones & $\mathrm{I}(0.2)$ \\
\hline Visited Sudan less than a year ago & $\mathrm{I}(0.2)$ \\
\hline Deferred previously & $\mathrm{I}(0.2)$ \\
\hline Prison & $\mathrm{I}(0.2)$ \\
\hline Wounds on hand & $\mathrm{I}(0.2)$ \\
\hline Human Immunodeficiency Virus (HIV) & $\mathrm{I}(0.2)$ \\
\hline On Anticoagulant & $\mathrm{I}(0.2)$ \\
\hline Sick & $\mathrm{I}(0.2)$ \\
\hline Total & $213(42.60 \%)$ \\
\hline
\end{tabular}

"altruistic intentions", and they believe themselves as healthy entities, though some of these contributors may be unfit to donate blood. Hence, it is the duty of the blood bank centers to recognize these unfit donors and defer them provisionally or permanently.

In our study, it has been found that $11.6 \%$ were refused to donate due to cupping. Similarly, Abdelaal et al ${ }^{12}$ found that 
$7.3 \%$ were refused due to cupping. The widespread practice of cupping reflects the religious beliefs of the Saudi population in the fact that cupping can manage a variety of diseases. ${ }^{16}$

It has also been found in our study that $5.80 \%$ were deferred due to less hours of sleep at night. Abdelaal et al ${ }^{12}$ also found that inadequate sleep was one of the commonest causes of deferral (6\%). This may reflect the unhealthy sleeping habits in the Saudi population, as also concluded in previous studies done specifically in Jeddah and generally in the Middle East. ${ }^{15,18}$

Our study showed that $13.6 \%$ were rejected due to low blood pressure. Similarly, Abdelaal et a ${ }^{12}$ reported $12 \%$ were rejected due to the same cause. The low blood pressure could be due to the anxiety experienced prior to donation. Various studies have shown that low blood pressure is associated to anxiety. ${ }^{14,17}$

Low hemoglobin as a cause of blood donor refusal accounted for $10.8 \%$ in this study. This is similar to that reported in other studies done in Turkey, India, Singapore, Dubai and Dammam, especially among females. ${ }^{711}$ This could be due the menstrual loss of blood in the childbearing age group and consumption of low-iron diet.

In a study which was also conducted in Jeddah, Abdelaal et $\mathrm{al}^{12}$ illustrated that deferral due to high hemoglobin was $0.4 \%$, which was not as common as what has been found in our study, which showed $7 \%$ rejection due to high hemoglobin. They were mostly males, and their hemoglobin levels ranged from 17 to $21 \mathrm{~g} / \mathrm{dL}$. The reason why high hemoglobin was not reported as a cause of deferral in the previous study done in southern Jeddah may be due to the differences between the criteria of both centers for donor deferral. Since smoking is more common among males than females, a possible cause of high hemoglobin levels in males could be smoking, as concluded in multiple previous studies conducted in the years 2016, 2012 and 1990..$^{20-23}$

Other studies showed slight differences in the commonest deferral causes, such as a study that was done in the USA that reported sore throat or having a cold or high temperature as the common causes of deferral, which were not much significant in our study. ${ }^{19}$

Unlike the findings of this study, a study that was conducted in Singapore showed that infectious diseases such as hepatitis, recent infection with measles and recent sexual activity which increased the risk of sexually transmitted diseases were major causes of blood donor deferral. ${ }^{9}$ Sexually transmitted diseases are generally low in Kingdom of Saudi Arabia compared to that in other countries worldwide, which is due to religious teachings, ${ }^{27}$ however, there are higher risks of being exposed due to traveling abroad. ${ }^{24}$

People were rejected due to history of visiting Africa or Sudan particularly, mainly because they are known endemic areas for malaria and HIV. ${ }^{25,26}$ There was a study done in Sudan that showed an incidence of 9 million episodes of malaria and 44,000 deaths, all in the year 2002. ${ }^{25}$

The similarities and variations seen between studies conducted on causes of blood donor rejection may be due to the different geographic areas and the cultural, educational and socioeconomic factors.

\section{Conclusion}

Low blood pressure (13.6\%), cupping (11.6\%) and less hours of sleep in the night prior to donation (5.8\%) were the major causes of rejection in this study. Similarities and variations between the commonest causes of blood donor rejection may be due to the differences and similarities in the geographic area and in the cultural, educational and socioeconomic factors.

\section{Acknowledgments}

We would like to take this opportunity to express our profound gratitude and deep regards to King Abdullah Medical Complex in Jeddah for supporting our research by providing the data needed. We would also like to thank our teachers Dr Saeed Mohammed Al Amoudi, Dr Heba Tawfiq and Dr Enaam Junainah who all provided us with guidance throughout our journey while working on this research. Nevertheless, their supervision, insight and expertise which greatly assisted the research. Great thanks to Mr Abduljawad Albeshri and Miss Banan Alsagga for their assistance during data collection. We would also like to show our gratitude to our dear family members for their endless patience with us throughout our work.

\section{Disclosure}

The authors report no conflicts of interest in this work.

\section{References}

1. Tariq S, Tariq S, Jawed S, Tariq S. Knowledge and attitude of blood donation among female medical students in Faisalabad. $J$ Pak Med Assoc. 2018;68(1):65-70.

2. Department of Essential Health Technologies Blood Transfusion Safety Unit. Universal Access to Safe Blood Transfusion. Geneva: World Health Organization; 2008.

3. World Health Organization. Blood Donor Selection: Guidelines on Assessing Donor Suitability for Blood Donation. Geneva: World Health Organization; 2012:16-23.

4. Gillet P, Neijens E. An original approach to evaluating the quality of blood donor selection: checking donor questionnaires and analyzing donor deferral rate. Front Med. 2018;5:74. 
5. Katz L, Strong DM, Tegtmeier G, Stramer S. Performance of an algorithm for the reentry of volunteer blood donors deferred due to falsepositive test results for antibody to hepatitis B core antigen. Transfusion. 2008;48(11):2315-2322.

6. Gonçalez TT, Sabino EC, Schlumpf KS, et al. Analysis of donor deferral at three blood centers in Brazil. Transfusion. 2013;53(3):531-538.

7. Arslan Ö. Whole blood donor deferral rate and characteristics of the Turkish population. Transfus Med. 2007;17(5):379-383.

8. Bahadur S, Jain S, Goel RK, Pahuja S, Jain M. Analysis of blood donor deferral characteristics in Delhi, India. Southeast Asian J Trop Med Public Health. 2009;40(5):1087-1091.

9. Lim JC, Tien SL, Ong YW. Main causes of pre-donation deferral of prospective blood donors in the Singapore Blood Transfusion Service. Ann Acad Med Singapore. 1993;22(3):326-331.

10. Al Shaer L, Sharma R, Abdulrahman M. Analysis of blood donor predonation deferral in Dubai: characteristics and reasons. J Blood Med. 2017;8:55-60.

11. Bashawri LA. A review of predonation blood donor deferrals in a university hospital. J Family Community Med. 2005;12(2):79-84.

12. Abdelaal M, Anwar F. Analysis of blood donor deferral in Jeddah, Saudi Arabia: characteristics and causes. J Pak Med Assoc. 2016;66(11): 1392-1395.

13. aabb.org [homepage on the Internet]. Bathesda: AABB Blood FAQ. 2019. Available from: http://www.aabb.org/tm/Pages/bloodfaq.aspx. Accessed August 18, 2017

14. Hildrum B, Mykletun A, Holmen J, Dahl AA. Effect of anxiety and depression on blood pressure: 11-year longitudinal population study. Br J Psychiatry. 2008;193(2):108-113.

15. Merdad RA, Merdad LA, Nassif RA, El-Derwi D, Wali SO. Sleep habits in adolescents of Saudi Arabia; distinct patterns and extreme sleep schedules. Sleep Med. 2014;15(11):1370-1378.
16. Qureshi NA, Ali GI, Abushanab TS, et al. History of cupping (Hijama): a narrative review of literature. J Integr Med. 2017;15(3):172-181.

17. Hildrum B, Mykletun A, Stordal E, Bjelland I, Dahl AA, Holmen J. Association of low blood pressure with anxiety and depression: the Nord-Trøndelag Health Study. J Epidemiol Community Health. 2007;61(1):53-58.

18. Fowler PM, Paul DJ, Tomazoli G, Farooq A, Akenhead R, Taylor L. Evidence of sub-optimal sleep in adolescent Middle Eastern academy soccer players which is exacerbated by sleep intermission proximal to dawn. Eur J Sport Sci. 2017;17(9):1110-1118.

19. Halperin D, Baetens J, Newman B. The effect of short-term, temporary deferral on future blood donation. Transfusion. 1998;38(2): 181-183.

20. Moradi-Lakeh M, El Bcheraoui C, Tuffaha M, et al. Tobacco consumption in the Kingdom of Saudi Arabia, 2013: findings from a national survey. BMC Public Health. 2015;15(1):611.

21. Jasim WM. Effect of tobacco smoking on hemoglobin level among Kirkuk Technical Institute Students. Med J Babylon. 2016;13(3).

22. Shah BK, Nepal AK. The effects of cigarette smoking on hemoglobin levels compared between smokers and nonsmokers. Sunsari Tech Coll J. 2012;1.

23. Nordenberg D, Yip R, Binkin NJ. The effect of cigarette smoking on hemoglobin levels and anemia screening. JAMA. 1990;264(12):1556-1559.

24. Madani TA. Sexually transmitted infections in Saudi Arabia. BMC Infect Dis. 2006;6(1):3.

25. Abdalla SI, Malik EM, Ali KM. The burden of malaria in Sudan: incidence, mortality and disability-adjusted life-years. Malar J. 2007;6(1):97.

26. Mendelson M. The geography of infectious diseases in Africa: from endemic populations to travelers. Int J Infect Dis. 2014;21:12.

27. Hamdi S. The impact of teachings on sexuality in Islam on HPV vaccine acceptability in the Middle East and North Africa region. J Epidemiol Glob Health. 2018;7(Suppl 1):S17-S22.
Journal of Blood Medicine

\section{Publish your work in this journal}

The Journal of Blood Medicine is an international, peer-reviewed, open access, online journal publishing laboratory, experimental and clinical aspects of all aspect pertaining to blood based medicine including but not limited to: Transfusion Medicine; Blood collection, Donor issues, Transmittable diseases, and Blood banking logistics; Immunohematology; Artificial and alternative

\section{Dovepress}

blood based therapeutics; Hematology; Biotechnology/nanotechnology of blood related medicine; Legal aspects of blood medicine; Historical perspectives. The manuscript management system is completely online and includes a very quick and fair peer-review system. Visit http://www.dovepress.com/ testimonials.php to read real quotes from published authors. 